\title{
Effects of a School-Based Relaxation Intervention on Recovery in Young Elite Athletes in High School
}

\author{
Johan Michael WIKMAN, PhD・Knud RYOM
}

Reinhard STELTER, PhD• Anne-Marie ELBE, PhD

\begin{abstract}
7 his study reports the effects of a recovery intervention in young
1 elite athletes in high school. The scissors model (Kellmann \& Kallus, 2001) was used as a theoretical foundation for the intervention. An intervention group $(\mathrm{n}=40)$ participated in 12 weekly intervention sessions, while the control group $(n=58)$ did not. A Danish version of the Recovery-Stress Questionnaire for Athletes measured recovery levels in the participants, at baseline and at the end of intervention. Qualitative interviews were conducted with four of the participants. Quantitative results did not show an improvement in recovery and stress levels. Qualitative results showed that the intervention had an effect on the participants, and also revealed areas, in which the intervention could be improved. Suggestions for future interventions are given.
\end{abstract}

Keywords: interview, sport psychology, talent, questionnaire 
Effects of a School-Based Relaxation Intervention on Recovery in Young Elite Athletes in High School

This study investigated the effects of a twelve-week recovery intervention on the recovery of young elite athletes in their high school years and discusses recommendations for future relaxation interventions.

Research has shown that adult elite athletes experience stress (Arnold \& Fletcher, 2012; Tabei, Fletcher, \& Goodger, 2012). Over time, exposure to excessive stress can result in burnout, a psychological, emotional, and physical withdrawal from a formerly pursued and enjoyable sport (Gould, Udry, Toffey \& Loehr, 1996a). But also young athletes experience a great deal of stress (Gustaffson, Kenttä, Hassmén, \& Lundqvist, 2007; Kenttä, Hassmén, \& Raglin, 2001). For example, Cohn (1990) investigated junior golfers by the use of qualitative interviews and found that all experienced stress and burnout to some degree in their career. Similarly, Coakley (1992) conducted interviews with young athletes who had dropped out and found that the athletes experienced constraints to their identity development and control over their lives. Gould, Udry, Tuffey, and Loehr (1996a, 1996b) did a comparison study between burned out and non-burned out young tennis players and concluded that one reason for burnout was the higher experienced stress in the burnouts. They found that all of their participants reported psychological reasons for burnout, $90 \%$ reported social reasons and 50\% reported logistic reasons. Similarly, Radeke and Smith (2004) found that perceived stress, general coping behaviours and social support satisfaction all had a negative relationship with stress and burnout in adolescent athletes. Smith, Gustafsson, and Hassmén (2010) also found several social variables connected to burnout in adolescent athletes. It seems fair to conclude that stress and burnout is a problem for many talented youth sport participants, and it seems to be connected to psychological and social challenges.

The same picture emerges when turning to the school context (Compas, Connor-Smith, Saltzman, Thomsen, \& Wadsworth, 2001). Several studies have investigated sources of stress in high school students. Day-to-day school stressors (grades as well as academic and achievement expectations) are cited among the most influential of contributors to stress in high school students (Crystal, Chen, Fuligni, Stevenson, Hsu, \& Ko, 1994; de Anda, Baroni, Boskin, Buchwald, Morgan, \& Ow, 2000; Lohman \& Jarvis, 2000). Byrne, Davenport, and Mazanov (2007) used a factor analysis on 58 distinct stressors reported by Australian youths. The result was at ten dimensions, four of which are school related; academic performance, attendance, interaction with teachers and balancing leisure time with school. Furthermore, adolescent life in general and the many transitions involved can also contribute to a high amount of stress in high school students (Elgar, Arlett, \& Groves, 2003; Isakson \& Jarvis, 1999). Overall, it seems fair to conclude that handling school life and elite sport in adolescence can be a stressful endeavour with potential negative consequences 
if not addressed properly (Compas, Orosan, \& Grant, 1993). With the challenges of balancing two time consuming and potentially stressful parts of life, it is no wonder that some young talented athletes experience stress.

This have also been investigated in dual career research, where dual career is defined as "a career with the major foci on sport and studies or work" (Stambulova \& Wylleman, 2015, p. 1). This area has experienced a strong interest in Europe since the 1990s (De Knop, Wylleman, Van Houcke, \& Bollaert, 1999) and to the present date combining elite sport and education is still perceived challenging for many athletes, but notably also with positive consequences if the athletes receives support through the process (Kristiansen, 2016). Hence, it seems important that young talented athletes handles the stress posed by a dual career with sport and studies well, and knowledge on stress reducing interventions is needed.

\section{Current knowledge of stress reducing interventions}

The research area of stress is a vast topic in psychology as well as in the sport research field. But the area of adolescent coping with stress, sport and school is a relative unstudied theme. A few studies, to our knowledge, has been made, which will be presented in this section. But due to the relative low number of studies, this article will first present reviews from the broader sport research field of stress, followed by the more specific intervention studies found important to this study.

Rumbold, Fletcher and Daniels (2012) conducted a review investigating psychosocial interventions aimed at stress management in competitive sport performers. A total of 64 studies were included, and their findings showed that in general, a variety of stress management interventions were applied, to optimize stress experience and enhance performance (Rumbold, Fletcher and Daniels, 2012). Overall, this review found that multimodal programs and design features of the intervention were important areas to consider, when creating an intervention.

Sarkar and Fletcher (2014) published a review investigating stressors athlete encounter and protective factors which helps them to handle such demands. They found three overall stressors labelling these; competitive, organisational and personal stressors. Drawing on psychological resilience, they proposed five protective factors; positive personality, motivation, confidence, focus and perceived social support (Sarkar \& Fletcher, 2014). 
In the only review to our knowledge, on interventions targeting stress and adolescents (but not in the sport context), Rew, Johnson and Young (2014) found evidence to support the effectiveness of interventions using development of cognitive skills with participants. This review was based on relative few studies and the review pointed to the need for more research to develop adolescent's capacity to handle stress (Rew, Johnson and Young, 2014).

A call for more intervention studies is evident and especially in the field of sports, where a very limited number of studies have been published. The few studies published are studies working with various techniques, like relaxing music to reduce anxiety (Elliott, Pulman and Taylor, 2014), yoga and mindfulness to reduce stress (Baer, 2003), emotional and behavioural difficulties (Goodman et al., 2014) and life-skills programs to achieve balance and managing stress (Hardcastle et al., 2014). More research is needed, making the study presented in this article highly relevant. In the present study, a recovery intervention was attempted to increase recovery in the young talented athletes.

\section{A Model for the Intervention}

Kellmann and Kallus' scissors model (2001) was chosen as a theoretical point of departure for the intervention. The model and theoretical considerations will be described in this paragraph. Perceiving the person as an organism in interplay with the context, in which he or she is embedded, Kellmann and Kallus operates with the following definitions of stressors, stress and recovery.

A stressor is an objective factor, affecting the athlete from the outside. It can be a physiological as well as a psychological factor. A stressor can be viewed as both good and bad, depending on the response to it. For example, training helps increase sporting capacity and performance, which is a desired outcome. However, if the athlete does not get adequate time to recover, sporting capacity and performance will decrease over time.

Stress is the effect of a given stressor in the athlete. It is defined by the athlete's individual interpretation of the stressor. Continuing the training example, an athlete who is very fit will interpret a hard training bout as a good workout, while the unfit athlete will interpret it as too hard and will need several days to recover.

Recovery is the process, during which the athlete returns to a state of physiological and psychological balance. Kellmann and Kallus describe it as “... an inter- and intra-individual multilevel (e.g., psychological, physiological, social) process in time for the re-establishment of performance abilities. Recovery includes an action-oriented component, and those self-initiated 
activities (proactive recovery) can be systematically used to optimize situational conditions to build up and to refill personal resources and buffers" (2001, p. 22). In the training example, recovery activities can be as simple as rest and eating, but can also be stretching, cold water immersion or even recovery training. The key features of recovery are that recovery 1 ) is a process in time and depends on the type and duration of stress, 2) depends on a change in, reduction of, or break from stress, 3 ) is specific to the individual and depends on individual appraisal, 4) can be passive, active or proactive, and 5) is closely tied to situational conditions (Kellmann, 2010).

The scissors model assumes that an accumulation of stress (from the interpretation of stressors) leads to a changed psychophysical state of the individual. The consequences of this changed state are changes in the athlete's ability to perform along with their capacity to adapt to subsequent stressors. If too many stressors are placed on the individual, and/or if he/she copes poorly with these stressors, it is likely that well-being will suffer and performance will decrease. However, if the athlete gets enough recovery, a high amount of stress can be handled. If the recovery of an athlete is of equal magnitude as the stress, the athlete will cope well. To put it shortly, if an individual handles stressors well and has possibilities for effective recovery, he or she will be able to handle a high amount of physical and psychological stressors, such as heavy training loads and pressure to perform well in school and in competitions (Kellmann, 2010).

Kellmann and Kallus do not perceive stressors to be good or bad, but simply that stressors affect the athlete's stress level. If the stressor is small or interpreted as small, the amount of stress induced is low. If the stressor is large or interpreted as large, the amount of stress induced in the athlete is large. A low amount of stress requires little or no recovery, while a high amount of stress requires extensive recovery. An individual can only be defined as "stressed out" in one way or the other, if he or she does not get the adequate amount of recovery. And if this continues over time, there is a risk of burnout (Kellmann \& Kallus, 2001).

High demands with regards to sport and school performance, together with lack of time and control over the athlete's life, has been identified as main stressors for young athletes in high school (Cohn, 1990; Gould et al., 1996a, 1996b; de Anda et al., 2000). In addition, it seems that the stress levels are affected by training load. Faude, Kellmann, Ammann, Schnittker, and Meyer (2011) investigated seasonal changes in high level football and found that preseason levels of stress were significantly lower than in-season levels. Similarly, Jürimäe, Mäestu, Purge, and Jürimäe (2004), as well as Kellmann, Altenburg, 
Lormes, and Steinacker (2001), found elevated stress levels during periods with high training loads in rowers. To counter these stressors, it would be advisable to decrease training load or homework assignments in these given periods. This includes changing season and school year planning as well as training and homework load. Given the fact that the individual often has little influence over the educational and sporting system he or she operates within, it seems difficult to reduce the stressors from school or sport.

Instead, an intervention can focus on the recovery of an individual. If the amount of stress is high, an equal amount of recovery is needed in order to cope with this. According to the Scissors model (Kellmann \& Kallus, 2001), recovery activities can help reduce the amount of stress experienced by the young athletes. Therefore, this intervention focused on the recovery of young athletes in high school.

\section{Aim of the Study}

Recognizing that stress and potential burnout is often a concern for many young talented athletes, the aim of this study was to investigate the effects of a recovery intervention on the recovery levels in young talented athletes attending high school. Our hypothesis was that from baseline to end of intervention, levels of recovery would increase in the intervention group compared to the control group. This was based on the assumption that the intervention would increase levels of recovery through better understanding and more effective usage of recovery activities, both individual activities and relaxation techniques.

\section{Methods}

\section{Participants}

The participants were a convenience sample of students aged 16-19 in a Danish high school specialised for elite sports. They were competing in different sports, all the highest national level, and had 15-30 training and competition hours per week. The intervention group consisted of 19 students from a secondyear class in the spring term, and 23 students from a second-year class in the fall term. The control group consisted of a class of 27 second-year students in the spring term and a class of 31 second-year students in the fall term. During the intervention period, one participant from the intervention group and one from the control group dropped out, both for reasons not connected to the study. Hence, the study included 41 participants $(24$ male and 17 female, mean age $=$ $17.02, \mathrm{SD}=0.64)$ in the intervention group and 57 in the control group (40 male and 17 female, mean age $=16.98, \mathrm{SD}=0.51)$. 
Prior to the start of the intervention, informed consent was obtained from parents of participants under 18 years of age at the intervention start. All participants were informed orally of the aim of the research project, that data would be treated confidentially, and that they could drop out of the study at any time without consequences. Ethical approval from the ethical commission is only needed for invasive studies in Denmark, thus not needed for this study.

\section{The Recovery Intervention}

The participants assigned to the intervention group participated in 60-minute sessions once per week. The intervention period was twelve weeks, as this was the longest period, in which the intervention could be performed, before it would be interrupted by exams or vacation periods. All intervention sessions were carried out by the first author, and took place as a school activity during school time in a classroom or in the gym at the school. The form of the sessions was short presentations given by the first author, group discussions, assignments performed individually or in groups of varying size and relaxation exercises done with the full group.

The content and progression of the intervention was based on the scissors model (Kellmann \& Kallus, 2001). To increase awareness of stress and recovery, the first author introduced the concepts of stress and recovery and discussed several stressors and scenarios, in which these stressors could have a big impact. Furthermore, a number of stressors related to significant others, and the reasons for their behaviour were discussed, to gain better understanding of the source of the stressors.

To increase participants' ability to recover, action plans to counter stressors were discussed, and participants were asked to formulate recovery activities to increase recovery related to each potential stressor. Useful recovery activities were discussed both in smaller groups and bigger groups, to give the athletes understanding of recovery and a wide array of fitting recovery activities to choose from.

The amount of recovery in the athlete can also be increased by employing relaxation techniques (Kellmann \& Kallus, 2001). Therefore, it was decided to teach the young athletes a number of easy relaxation techniques, giving them tools to counter their experienced stress. Breathing exercises were chosen due to their accessibility to inexperienced participants (Williams \& Harris, 2006). In addition, progressive muscle relaxation exercises were chosen, because they are easy to use for participants who already a high amount of body awareness (Williams \& Harris, 2006), due to their involvement in high-level sports. The first author practiced the breathing exercises and progressive muscle relaxation exercises with the participants during the sessions. As homework, the participants were asked to rehearse these on their own in other settings than the school. 
Effects of a School-Based Relaxation Intervention on Recovery in Young Elite Athletes in High School

\section{Measurements}

A Danish version of the Recovery-Stress Questionnaire for Athletes (RESTQ-Sport, Elbe, 2008), based on an English version by Kellmann and Kallus (2001), was used to measure recovery and stress levels of the participants. The RESTQ-Sport contains 76 items, measuring 19 subscales of recovery and stress. Each subscale contains four items that asks the respondent to state how often he or she felt, thought or behaved in a certain way. An example of a question from the RESTQ-Sport is "In the past (3) days/nights I did not get enough sleep". The respondent can answer with a Likert-scale format where answers range from 0 (never) to 6 (always). The values for each subscale range from 0 (very low) to 24 (very high).

The subscales can be assigned to four super-scales of recovery and stress. The subscales General Stress, Emotional Stress, Social Stress, Conflicts/Pressure, Fatigue, Lack of Energy and Physical Complaints are assigned to the super-scale General Stress. The subscales Success, Social Recovery, Physical Recovery, General Well-Being and Sleep Quality are assigned to the super-scale General Recovery. The subscales Disturbed Breaks, Emotional Exhaustion and Injury are assigned to the super-scale Sport-specific Stress. And the subscales Being in Shape, Personal Accomplishment, Self-Efficacy and Self-Regulation are assigned to the super-scale Sport-specific Recovery (Kellmann \& Kallus, 2001).

The questionnaire has demonstrated satisfactory internal consistency, testretest reliability, and ecological validity, and has been used with various sports and nationalities (González-Boto, Salguero, Tuero, Márquez, \& Kellmann, 2008; Kellmann, 2010). The Danish version has also shown satisfactory reliability (Elbe, 2008).

As this study investigated the effects of an intervention on recovery, only the subscales belonging to the super-scales General Recovery and Sport-specific Recovery were used. The questionnaire was distributed to the participants at baseline and when the intervention ended-12 weeks after the start. Participants, who were not present when the questionnaire was distributed, were either approached on the same day the following week or emailed the questionnaire to fill out at home and return by email. Some participants were not present and did not return the filled out questionnaire by email, leaving missing data points. These were two participants from the intervention group, and 11 participants from the control group. 


\section{Statistical Analysis}

All data was analysed using IBM SPSS 23. Participants who had not filled out the questionnaire or parts of it at a given measuring point were excluded from the analyses that included that particular measuring point. Super scales were calculated by taking the mean of the sub-scales included in the sub-scales (sub-scales with unacceptable Cronbach's alpha values were excluded from the super-scales). Subscale internal consistency for all subscales and super scales was tested with Cronbach's alpha test, with an acceptable threshold of .70 (Streiner \& Norman, 2008). T-tests were used to investigate if there were any baseline differences between the groups in age and recovery scores. Effects of the recovery intervention on the subscales and super scale measures of recovery were analysed by using multiple regression models to investigate if group membership could predict mean recovery scores after the 12 -week intervention, adjusting for baseline scores of each output. In order to consider the influence of family-wise errors on the results, it was decided to also display Bonferronicorrected $p$-values (Field, 2009). As the Bonferroni correction is perceived as too conservative with many variables (Field, 2009), it was decided to divide the variables into three families of variables and correct for family-wise errors within each family. The two recovery super-scale of the RESTQ-Sport were each perceived as a family, and the third family was the two recovery super-scales of the RESTQ-Sport, comprised of the four super-scales. $p$-value thresholds in each family were divided by the number of variables in the family. Unadjusted $p$-values are also presented in table 3 in the results section.

\section{Qualitative Interviews}

To gain insight into personal experiences and how the intervention were perceived, qualitative interviews with four of the participants in the intervention group were performed. The interviews were conducted by the second author, who had no involvement in planning or teaching the intervention sessions, and the interviews were transcribed by a professional transcriber to avoid bias (Kvale \& Brinkmann, 2007). The first author, who conducted the intervention sessions, was excluded from planning, conducting and transcribing the interviews. Four participants were chosen, two who seemed to respond well to the intervention (one male and one female), and two who seemed to respond poorly (one male and one female). This would provide insight into the intervention from both a positive and a negative perspective, as well as include both genders. The interviewees were aged 17 to 19, and were interviewed twice, halfway through the intervention and one week after the intervention. The interviews were conducted at the school, and interviewees participated voluntarily in their free time. A phenomenological approach, inspired by Giorgi (1985) and Smith et al. (2009), was used, in which participants' lived experiences of a phenomenon are investigated in order to capture the essence of the phenomenon. The interviews 
were performed with a semi-structured interview-guide (Kvale \& Brinkmann, 2007; Stelter, 2010), in which the subjects stress, stress handling, motivation, application of relaxation techniques, effect of the recovery intervention, the teacher of the intervention, and the form and organization of the intervention were included (in chronological order). Drawing on Giorgi (1985), Smith et al. (2009) and Kvale and Brinkmann (2007), transcripts were analysed in three phases. First, interviews were read to identify the themes connected to the intervention. These were application of intervention techniques, contextual considerations, effect of the recovery intervention, form and organization of the intervention, homework, participants and recruitment, stress and the teacher of the intervention (in alphabetical order). Second, all significant interview statements connected to a specific major theme were clustered together and used to describe participants' lived experiences of that theme. Third, significant interview statements of the participants' lived experiences were used to write a composite description of each major theme. These are presented in the results section.

\section{Results}

\section{Data Quality}

The subscales Success, Social Recovery, Physical Recovery and Personal Accomplishment did not show acceptable levels of internal consistency. In the subscale Social Recovery, the low values could be improved to an acceptable level by removing one of the items. Although it is generally advised not to alter pre-constructed scales (Streiner og Norman, 2008), it was decided to do so in order to increase reliability of the results. Table 1 displays the Cronbach's alpha values for the subscales in the RESTQ-Sport, both for the original scales and the modified Social Recovery scale. The scales with Cronbach's alpha values of .70 or above were accepted and used in the further effect analysis (Streiner og Norman, 2008). The scales with one or more Cronbach's alpha values of below .70 were discarded. This was the case for the sub-scales Success, Physical Recovery and Personal Accomplishment. 
Sport Science Review, vol. XXV, No. 3-4, September 2016

\begin{tabular}{lcccc} 
Scale & \multicolumn{2}{c}{ Baseline } & \multicolumn{2}{c}{ End of intervention } \\
\hline Subscale & $\mathrm{n}$ & Cronbach's alpha & $\mathrm{n}$ & Cronbach's alpha \\
\hline Success & 97 & .394 & 84 & .519 \\
Social recovery & 98 & .749 & 85 & .661 \\
Social recovery & 98 & .799 & 85 & .773 \\
(modified) & 97 & .606 & 86 & .642 \\
Physical recovery & 98 & .836 & 85 & .696 \\
General well-being & 97 & .837 & 84 & .744 \\
Sleep quality & 97 & .737 & 85 & .713 \\
Being in shape & 91 & .609 & 84 & .647 \\
Personal accomplishment & 98 & .784 & 82 & .792 \\
Self-efficacy & 97 & .814 & 83 & .793 \\
Self-regulation & 95 & .885 & 82 & .826 \\
\hline General recovery & 91 & .898 & 79 & .893 \\
Sport-specific recovery & 97 & & \\
\hline
\end{tabular}

Table 1 - Cronbach's Alpha Values for the Subscales in the RESTQ

\begin{tabular}{lllll}
\hline Variable family & Test variable & $\begin{array}{l}\text { Intervention } \\
\text { group value (SD) }\end{array}$ & $\begin{array}{l}\text { Control group } \\
\text { value (SD) }\end{array}$ & p value \\
\hline $\begin{array}{l}\text { General } \\
\text { recovery }\end{array}$ & Social recovery & $4.05(0.96)$ & $3.81(1.99)$ & .241 \\
& General well-being & $3.92(1.05)$ & $3.52(0.93)$ & .052 \\
& Sleep quality & $3.99(1.25)$ & $3.94(1.38)$ & .880 \\
\hline $\begin{array}{l}\text { Sport-specific } \\
\text { recovery }\end{array}$ & Being in shape & $3.12(1.13)$ & $2.91(1.05)$ & .336 \\
& Self-efficacy & $3.332(1.27)$ & $3.07(1.23)$ & .344 \\
\hline Super-scale & General recovery & $3.60(0.75)$ & $3.47(1.00)$ & .492 \\
& $\begin{array}{l}\text { Sport-specific } \\
\text { recovery }\end{array}$ & $3.03(1.06)$ & $2.90(0.98)$ & .550 \\
\hline
\end{tabular}

Table 2 - T-Test of Group Differences in Baseline Recovery Scores 
Effects of a School-Based Relaxation Intervention on Recovery in Young Elite Athletes in High School

\section{Statistical Results}

The t-test revealed that there were no differences between the groups in age (mean difference $=0.04, p=.741$ ) and baseline recovery scores. The baseline recovery score test results can be seen in table 2 .

Table 3 shows that the intervention did not have any effect on the intervention group compared to the control group. There was no effect over time from the intervention designed for this study. This was contrary to our hypothesis: that recovery levels would increase and stress levels would decrease in the intervention group from the beginning to the end of the intervention.

\begin{tabular}{lllll}
\hline Variable family & Test variable & B & $95 \%$ CI & $\begin{array}{l}\text { Adjusted p-value } \\
\text { (unadjusted p-value) }\end{array}$ \\
\hline General recovery & $\begin{array}{l}\text { Social recovery } \\
\text { General }\end{array}$ & -0.11 & $-0.28 ; 0.05$ & $.720(.180)$ \\
& $\begin{array}{l}\text { well-being } \\
\text { Sleep quality }\end{array}$ & 0.01 & $-0.15 ; 0.18$ & $>1(.880)$ \\
\hline $\begin{array}{l}\text { Sport-specific } \\
\text { recovery }\end{array}$ & Being in shape & 0.11 & $-0.07 ; 0.29$ & $.960(.240)$ \\
& Self-efficacy & 0.27 & $0.03 ; 0.51$ & $.112(.028)$ \\
& Self-regulation & 0.19 & $-0.04 ; 0.41$ & $.416(.104)$ \\
\hline Super-scale & General Recovery & 0.05 & $-0.08 ; 0.17$ & $>1(.483)$ \\
\hline $\begin{array}{l}\text { Sport-specific } \\
\text { recovery }\end{array}$ & 0.19 & $0.01 ; 0.38$ & $.152(.038)$ \\
\hline
\end{tabular}

Table 3 - The Effects of the Relaxation Intervention on the Test Variables

Note. Data are presented as mean differences after the intervention, adjusted for baseline scores of each test variable. $\mathrm{CI}=$ Confidence interval. $p$-values are displayed with Bonferroni correction (unadjusted $p$-values).

\section{Qualitative Results}

Overall, the composite descriptions of the major themes suggest that the intervention was successful. The composite descriptions of each major theme emerging from the analysis can be found below. 


\section{Application of intervention techniques.}

All interviewees reported that they had used the relaxation techniques to some extent, but the overall picture emerging was that they were not applied systematically, but when it was deemed fit. Where the breathing exercises were applied to some extent by all interviewees, the muscle relaxation exercises and the planning exercises where applied more sporadically, and not without problems. Specifically, the interviewees that tried planning their schedule had already done that to some extent before the intervention, and the interviewees felt that the muscle relaxation exercise had varying effects. Some of the interviewees reported that they forgot to apply or rehearse the exercises in situations where it could have been beneficial.

The situations, in which the relaxation techniques were used, can be divided into three areas: before sleep, in daily situations, and in their sport. There was an overall consensus that the relaxation exercises were useful, when they wanted to get into a relaxed state before they went to sleep. One interviewee stated that he thought that the purpose of the relaxation exercises was to become tired, while another stated in the interview halfway through the intervention that he only applied the relaxation exercises before he went to sleep. However, in the interviews after the intervention, it seems that the application had spread to more contexts. The interviewees felt that they could use the relaxation techniques in daily situations that imposed a lesser degree of stress. Here, the breathing exercises were used not only as body-to-mind exercise, but also as means to think clearly about the situation or to progress from one situation to the next. The interviewees also reported using the relaxation techniques in their sport. Again, they were not applied systematically, but where it seemed to fit and there was an expectation that they would be efficient. One interviewee reported that the application had helped in a particularly stressful competition situation, while another reported a similar effect that seemed to vanish quickly. The interviewees stated that they thought that the relaxation exercises were useful in many different situations, but did not seem to use them in most of these situations, either because they didn't think about it or didn't experience any of these situations during the intervention period.

\section{Contextual considerations.}

With regard to how and where the intervention sessions were held, it was stated that it was better to have the sessions scheduled as a part of the school activities, contrary to have the sessions scheduled in the free time of the participants. There was an overall consensus that the school context was a good place to have the sessions and to test the relaxation techniques. Where one interviewee found that having the intervention sessions during school times was advantageous, because there would be time to think about them and how to use 
them before practice, another interviewee did not feel that the techniques could be successfully transferred to the sport context, suggesting that it would be more beneficial to have the intervention sessions in the sports club. Furthermore, timing and duration of the intervention period was discussed, were the interviewees felt that it would have been more purposeful and beneficial, if the intervention period had been longer and connected to an exam period, where stress is experienced to a higher degree.

\section{Effect of the recovery intervention.}

Overall, the interviewees felt that the intervention was effective. Asked whether the intervention had produced a large, medium or a small effect, one interviewee reported a large effect, two perceived the effect to be medium, and one interviewee reported a small effect. However, this interviewee suggested that the effect might be higher if he had put a larger effort into it. All interviewees reported that they felt an effect of varying duration, when they used the relaxation techniques. The breathing exercises were reported to be efficient by all interviewees. They felt that they became more relaxed, which was perceived desirable in the situations in which it was achieved. Especially when the interviewees went to sleep, it seemed to work well, but also in stressful situations, the breathing exercises could help to relax and gain control of emotions and/or the situation. Other reported effects were higher awareness, concentration and readiness. In stressful situations, this was perceived to be beneficial, but one interviewee reported that this also happened before going to sleep. The planning exercises were mentioned by two interviewees who reported that these also helped to alleviate their stress. The muscle relaxation exercises were reported to be used with mixed success. One interviewee stated that they did not work, while another said that one of them was too long and suggested that it should be practiced for a longer period of time in order to be efficient. Two interviewees reported that the muscle relaxation exercise worked very well for them.

\section{Form and organization of the intervention.}

There was a general consensus that the intervention was relevant, because the purpose of the techniques employed was clear. Contrary to this, some interviewees stated that it was hard to see how the intervention would help the participants, as it was done in a period with no exams and hence, low levels of stress. Also, it was suggested by several interviewees that the intervention should be conducted more like a normal course in the school, with a longer intervention period, and where attendance was taken and grades were given. Interviewees also felt that the school context was an appropriate context for such an intervention, preferred over an intervention in their free time, but that it could be hard to transfer the techniques to the sport context. The interviewees 
also felt that one or two sessions per week was an appropriate amount of time spent on it. One interviewee suggested that there should be a follow-up session every second month to secure application of the techniques, while another interviewee suggested that the intervention should be a voluntary offer to all high school students who are also competing in elite sports, because it will produce participants who believe in the effects. The organization of the intervention and structure of the sessions was perceived as good. The interviewees felt that the sessions had a good progression and an appropriate mix of theory and practice. They also felt that the sole focus on relaxation was good and that the mix of breathing, muscle relaxation and planning exercises were fitting, although some of the interviewees stated that not all exercises were novel to them or worked well for them. The progressive muscle relaxation exercise was mentioned specifically, as it seemed that this exercise was not introduced early enough for the participants to learn it. Some of the interviewees stated that the homework was a burden for them, or that some of the exercises resembled repetitive training rather than learning, and that this had a negative impact on their motivation.

\section{Homework.}

The interviewees emphasized that completion of the homework assignments was an important prerequisite for benefitting from the intervention sessions. However, only the interviewees that could see a purpose with the intervention stated that they could handle the amount of homework, and actually completed it. On the other hand, the interviewees that were not stressed did not see a purpose with the homework and hence perceived it to be an extra burden they didn't want to bother with.

\section{Participants and recruitment.}

The interviewees stated that they felt the intervention was useful for some, but not all participants. They suggested that participation should be voluntary, or that the intervention should have included grading in the end, so participants would have been more motivated for the intervention. The interviewees stated, regardless of whether their motivation for the intervention was high or low, that a voluntary recruitment would have increased overall effect of the intervention.

\section{Stress.}

The interviewees mentioned three main causes of stress: school, sport and persons that could have an impact on the interviewees' life world. The interviewees mentioned absent-mindedness, dizziness, insecurity, irritation, lack of control, lack of energy, nervousness, poor health, tension and unbalanced stomach as symptoms of stress. However, the intervention was conducted in periods with no exams, and only few sport competitions. Hence, the interviewees 
stated that they did not feel stressed. They reported mainly low levels of stress, and none of them had high levels of stress at any time during the intervention.

\section{Teacher of the intervention.}

The interviewees generally felt that the sport psychology consultant of the intervention was good. They stated that he seemed prepared, experienced, and was generally good at disseminating the subjects in natural way. One interviewee mentioned that the emails, in which the teacher distributed relaxation exercises and homework assignments, should be sent out sooner, so the participants had more time to complete them. Where one interviewee felt that it was nice that the teacher taught an informal way where the atmosphere was relaxed but with clear teacher and participant roles, another interviewee felt that the teacher conducted the intervention sessions in a too relaxed way that did not facilitate learning.

\section{Discussion}

The aim of this study was to investigate the effects of a 12 -week recovery intervention on stress and recovery in young elite athletes. The regression analysis indicated that there was no significant difference between the two groups after the intervention. This did not support our hypotheses: That recovery would increase and stress would decrease in the intervention group compared to control group during the intervention.

However, our qualitative analysis revealed that the intervention had an effect. Our hypothesis was not directly supported, as this would include an effect on participant recovery, but the intervention was reported to be effective. This disagreement between conclusions can be attributed to gathering and/or analysis of either the quantitative data or the qualitative data.

Only four interviewees were used for the qualitative interviews, and it cannot be ruled out that they are not representative of the intervention group. However, the interviewees were chosen to represent the sample best in terms of gender and how well they understood and participated in the sessions and exercises, and the qualitative interviews and the analysis of these were conducted in a way to avoid bias. Based on the quality of the interviews, we believe that the conclusions from the qualitative interviews concerning effectiveness of the intervention are trustworthy.

Concerning quantitative measurements, the effect measurement should be addressed. The part of the RESTQ-Sport used for the present study targets recovery. It does not assess the skills and learning experiences that the intervention targets, but rather the implications of these. As no instrument to measure if participants had learned what was intended in the intervention sessions, the RESTQ-Sport was used to measure the implications of the skills 
and learning experiences. However, it is possible that these implications need longer time to come into effect and could therefore not yet be measured after 12 weeks.

Turning to the quality of the data produced by the RESTQ-Sport, a number of things should be addressed. First, it should be noted that the questions in the RESTQ-Sport asks the respondent to which degree they agree with a statement concerning the last three days. The answers produced by the questionnaire depend heavily on which weekday and in what period they are distributed. Even though the questionnaires were distributed on the same time for control and intervention group, data could be contaminated if there are differences between the two groups. This could be differences in sport (and with that, differences in training schedule and season timing) or differences in class schedule. The wording of the RESTQ-Sport items makes it vulnerable to such timing effects, and this weakens the quantitative results.

Second, the sub-scales Success, Physical Recovery and Personal Accomplishment did not produce Cronbach's alpha values that met the demands of 0.70 . This is a concern, since the data produced by these subscales cannot be used for further analysis. With a high school sample, it is possible that the respondents could misinterpret some of the questions. However, none of the questions in the subscales seemed harder to understand than the rest of the questions in the RESTQ-Sport. It was also investigated if the questions of subscales with unacceptable Cronbach's alpha values did not fit the life world of the respondents. The sub-scale Personal Accomplishment is sport-specific, and can therefore only produce valid and reliable answers if the respondent has done any sports in the three days prior to filling out the questionnaire. If a respondent is injured, is in off-season or has not participated in the sport for the last three days, this is likely to produce random answers, thereby affecting the Cronbach's alpha values of the sub-scale.

In general, the RESTQ-Sport seems to have some weaknesses, and this should be taken into consideration, when quantitative data is analysed and concluded upon. We feel that the RESTQ-Sport should primarily be used for individual stress/recovery assessment, and that analysis of groups should be done with caution. This is in line with King, Clark and Kellmann (2010), who recommends individual assessment with the RESTQ-Sport. For the present study, we find it likely that the recovery intervention had an effect, but that our measurements failed to tap this effect. 
Effects of a School-Based Relaxation Intervention on Recovery in Young Elite Athletes in High School

While the intervention group participated in the recovery intervention, the control group did not participate in any extra activities. An alternate hypothesis is that any increases in recovery in the intervention group are due to the extra time spent together with the researcher. However, the intervention accumulated 12 hours of extra time spent together, over a 12-week period. Compared to at least 20 hours per week, at least 240 hours over the 12 weeks, 12 hours seem minuscule in comparison. Furthermore, the effect of increased time spent together on recovery has not been documented by research studies. And with the qualitative interviews, it could be investigated if this alternate hypothesis was plausible.

The composite descriptions of the major themes in the qualitative interviews reveal some things that went well in the intervention and some things that could be improved. The authors suggest a number of measures that should be taken in order to intervene successfully on stress and recovery of elite athletes in high school. These can be seen in Table 4 and are described here.

Recruitment

- Recruit on a voluntary basis to secure that only motivated subjects participate in the intervention

- Recruit an experienced expert to conduct the intervention sessions

Introduction to the intervention and its purpose

- State a clear purpose of the intervention to secure motivation. If the intervention is planned in a stressful period (see above), it should be made clear that the intervention can alleviate stress

- State a clear purpose of the exercises to make sure that the exercises are practiced and applied in situations, where they are useful

Form and organization of the intervention

- Plan a longer intervention period to secure that there is time to learn the relaxation techniques

- Plan the intervention like a normal course in school with taking attendance and grades to motivate subjects to participate actively

- Plan the intervention like a normal part of the participants' schedule, contrary to in their free time, to secure motivation. Another possibility is plan the intervention as a part of the sport context to increase motivation and transfer of the exercises to sport situations

- Plan the intervention so it matches with a stressful period in the participants' life to secure participant motivation

- Use one or two sessions per week. This seems like a fitting frequency

- Conduct follow-up sessions approximately every other month to secure continued application of the exercises 
Content, form and organization of the intervention sessions

- Focus only on relaxation, because this intervention topic is of sufficient size to stand on its own in an intervention

- Start with the breathing exercises, as these seems to be easy to apply

- Introduce muscle relaxation techniques early, so there is enough time to learn these properly, increasing the chance of a positive effect

- Secure a systematic application of the exercises, through rehearsal of these during the sessions, through homework and through conversations about when and how to apply them

- Help transfers to sport context

- Mix theory with practice, so the participants know the purpose and the effects of the exercises

- Homework can be given, but only if the participants know the purpose of the intervention together with why the exercises should be rehearsed, and if they are given enough time to do it

Table 4 - Suggestions for conducting successful interventions

Participants should be recruited on a voluntary basis in order to have higher participant motivation for an intervention. This seemed to have major importance with the interviewees. To match this with a randomized control trial, participants that have volunteered for the study should randomly be assigned to either a control or an intervention group. After the intervention period, the control group could receive a similar intervention in order to secure that all participants benefit from the intervention. Also, an experienced expert should be recruited to conduct the intervention.

The introduction to the intervention as a whole and to the specific intervention exercises should be clear, to secure motivation in the participants. Although it seems that the intervention and the exercises were introduced clearly, some of the interviewees misinterpreted the purpose of the intervention and some of the relaxation exercises, and this had an impact for their motivation to put effort into the exercises and the homework.

Turning to the form and the organization of the intervention, a number of points can be drawn out. The intervention period should be longer to secure impact of the intervention. Perhaps three months is too short a time frame for the intervention to have a measureable effect on the recovery of the participants. The intervention sessions should be scheduled in the school time (or perhaps in conjunction with their sport), contrary to in participants' free time, attendance should be taken and grades should be given, to secure motivation of the participants. The interviewees stated that this could have a positive impact 
on their motivation to participate. Also, the intervention period should be planned in or leading up to a period with stress for the participants. This should, according to the interviewees, make the purpose of the sessions more clear and increase motivation. Intervention sessions should be once or twice per week, as this seemed like a fitting amount of relaxation training for the interviewees. Lastly, follow-up sessions should be conducted every two months to secure continued application of relaxation techniques.

With regards to content, form and organization of the intervention sessions, some recommendations can be given. First of all, the focus of the intervention can be solely on stress and relaxation, as the interviewees felt that the subject was big enough to stand on its own. The breathing exercises should be introduced in the beginning, as these seem to have a high success rate with the interviewees. Also, enough time to learn the muscle relaxation exercises should be secured, either by a longer intervention period or by introducing them earlier in the process. Some interviewees felt that they did not have time to learn these more comprehensive exercises. A systematic rehearsal of the intervention should be secured, through rehearsal during intervention sessions, homework and reflections on how to use the relaxation techniques in practice. Some interviewees stated that homework would be easier to overcome if the purpose of the exercises was clear, and this could be achieved through these reflections. In addition, the participant's should be given more time to do their homework. Lastly, it was mentioned that the mix of theory and practice was good. Participants should be informed of the purpose of the relaxation techniques, and how they work, as well as they should be given the chance to apply them in practice.

In short, we believe that the above-mentioned intervention given to young elite athletes can be a useful way to create balance between recovery and stress. However, given the above results, three issues should be improved in future intervention designs. First, the questions should be investigated with a longer intervention period to let the intervention have an effect. Second, the intervention should be designed with the above intervention recommendations in mind. Third the instrument, in this case the RESTQ-Sport, should be altered to address its weaknesses and tested thoroughly before employing it in an intervention study. 


\section{References}

Arnold, R., \& Fletcher, D. (2012). A research synthesis and taxonomic classification of the organizational stressor encountered by sport performers. Journal of Sport \& Exercise Psychology, 34(3), 397-429.

Baer, R. A. (2003). Mindfulness training as a clinical intervention: a conceptual and empirical review. Clinical Psychology: Science and Practice, (10)2, 125-143.

Byrne, D. G., Davenport, S. C., \& Mazanov, J. (2007). Profiles of adolescent stress: The development of the Adolescent Stress Questionnaire. Journal of Adolescence, 30(3), 393-416. doi:10.1016/j.adolescence.2006.04.004

Coakley, J. (1992). Burnout among adolescent athletes: A personal failure or social problem? Sociology of Sport Journal, 9, 271-285.

Cohn, P. J. (1990). An exploratory study on sources of stress and athlete burnout in youth golf. The Sport Psychologist, 4(2), 95-106.

Compas, B. E., Connor-Smith, J. K., Saltzman, H., Thomsen, A. H., \& Wadsworth, M. E. (2001). Coping with stress during childhood and adolescence: Problems, progress, and potential in theory and research. Psychological Bulletin, 127(1), 87-127.

Compas, B. E., Orosan, P. G., \& Grant, K. E. (1993). Adolescent stress and coping: implications for psychopathology during adolescence. Journal of Adolescence, 16(3), 331-349. http://doi.org/10.1006/jado.1993.1028

Creswell, J. W. (2007). Qualitative Inquiry \& Research Design (2nd ed.) Thousand Oaks: Sage Publications, Inc.

Crystal, D. S., Chen, C., Fuligni, A. J., Stevenson, H. W., Hsu, C.-C., Ko, H.-J., ... Kimura, S. (1994). Psychological Maladjustment and Academic Achievement: A Cross-Cultural Study of Japanese, Chinese, and American High School Students. Child Development, 65(3), 738-753. doi:10.1111/j.1467-8624.1994. tb00780.x

de Anda, D., Baroni, S., Boskin, L., Buchwald, L., Morgan, J., \& Ow, J. (2000). Stress, stressors and coping among high school students. Children and Youth Services Review, 22(6), 441-463. doi:10.1016/S0190-7409(00)00096-7 
Effects of a School-Based Relaxation Intervention on Recovery in Young Elite Athletes in High School

De Knop, P., P. Wylleman, J. Van Houcke, and L. Bollaert. (1999). Sports management - a european approach to the management of the combination of academics and elite-level sport. In S. Bailey (Ed.), Perspectives - The Interdisciplinary Series of Physical Education and Sport Science. Vol. 1: School Sport and Competition (49-62). Oxford: Meyer \& Meyer Sport.

Elbe, A. M. (2008). The Danish version of the Recovery-Stress Questionnaire for Athletes. Unpublished Work.

Elgar, F. J., Arlett, C., \& Groves, R. (2003). Stress, coping, and behavioural problems among rural and urban adolescents. Journal of Adolescence, 26(5), 574-585. http://doi.org/10.1016/S0140-1971(03)00057-5

Elliott, D., Polman, R., \& Taylor, J. (2014). The effects of relaxing music for anxiety control on competitive sport anxiety. European Journal of Sport Science, 14(sup1), S296-S301. http://doi.org/10.1080/17461391.2012.693952

Faude, O., Kellmann, M., Ammann, T., Schnittker, R., \& Meyer, T. (2011). Seasonal changes in stress indicators in high level football. International Journal of Sports Medicine, 32(4), 259-265. doi:10.1055/s-0030-1269894

Field, A. (2009). Discovering statistics using SPSS (3rd ed.). London: Sage Publications Ltd.

Giorgi, A., Aanstoos, C., Fischer, W. F., \& Wertz, F. J. (1985). Phenomenology and psychological research: Essays by Christopher Aanstoos, William F. Fischer, Amedeo Giorgi and Frederick J. Wertz. Pittsburgh, PA: Duquesne University Press.

González-Boto, R., Salguero, A., Tuero, C., Márquez, A., \& Kellmann, M. (2008). Spanish adaptation and analysis by structural equation modelling of an instrument for monitoring overtraining: The Recovery-Stress Questionnaire (RESTQ-Sport). Social Behavior and Personality, 36(5), 635-650. doi:10.2224/ sbp.2008.36.5.635

Goodman, F. R., Kashdan, T. B., Mallard, T. T. \& Schumann, M. (2014). A brief mindfulness and yoga intervention with an entire NCAA division I athletic team: An initial investigation. Psychology of Consciousness: Theory, Research, and Practice,1(4), 339-356. doi: 10.1037/cns0000022

Gould, D., Udry, E., Tuffey, S., \& Loehr, J. (1996a). Burnout in competitive junior tennis players: I. A quantitative psychological assessment. The Sport Psychologist, 10(4), 322-340. 
Gould, D., Udry, E., Tuffey, S., \& Loehr, J. (1996b). Burnout in competitive junior tennis players: II. Qualitative analysis. The Sport Psychologist, 10(4), 341-366.

Gustafsson, H., Kenttä, G., Hassmén, P., \& Lundqvist, C. (2007). Prevalence of burnout in competitive adolescent athletes. The Sport Psychologist, 21(1), 21 37.

Hardcastle, S. J., Tye, M., Glassey, R., \& Hagger, M. S. (2015). Exploring the perceived effectiveness of a life skills development program for highperformance athletes. Psychology of Sport and Exercise, 16(3), 139-149. http://doi.org/10.1016/j.psychsport.2014.10.005

Henriksen, K., Larsen, C. H., Storm, L. K., \& Ryom, K. (2014). Sport psychology interventions with young athletes: The perspective of the sport psychology practitioner. Journal of Clinical Sport Psychology, 8(3), 245-260. doi: 10.1123/ jcsp.2014-0033

Isakson, K., \& Jarvis, P. (1999). The adjustment of adolescents during the transition into high school: A short-term longitudinal study. Journal of Youth \& Adolescence, 28(1), 1-26. doi:10.1023/A:1021616407189

Jürimäe, J., Mäestu, J., Purge, P., \& Jürimäe, T. (2004). Changes in stress and recovery after heavy training in rowers. Journal of Science and Medicine in Sports, 7(3), 334-339.

Kellmann, M. (2010). Preventing overtraining in athletes in high intensity sports and stress/recovery monitoring. Scandinavian Journal of Medicine and Science in Sports, 20, 95-102.

Kellmann, M., Altenburg, D., Lormes, W., \& Steinacker, J., (2001). Assessing stress and recovery during preparation for the World Championships in rowing. The Sport Psychologist, 15(2), 151-167.

Kellmann, M. \& Kallus, K. W. (2001). Recovery-Stress Questionnaire for Athletes. Champaign, IL: Human Kinetics.

Kenttä, G., Hassmén, P., \& Raglin, J. S. (2001). Trinaing practices and overtraining syndrome in Swedish age-group athletes. International Journal of Sports Medicine, 22(6), 460-465. doi: 10.1055/s-2001-16250 
Effects of a School-Based Relaxation Intervention on Recovery in Young Elite Athletes in High School

King, D., Clark, T., \& Kellmann, M. (2010). Changes in stress and recovery as a result of participating in a premier rugby league representative competition. International Journal of Sports Science and Coaching, 5(2), 223-237.

Kristiansen, E. (2016). Walking the line: how young athletes balance academic studies and sport in international competition. Sport in Society. doi:10.1080/ 17430437.2015.1124563

Kvale, S. \& Brinkmann, S. (2007). Interview (2nd ed.). København: Hans Reitzels Forlag.

Lohman, J. B. \& Jarvis, P. A. (2000). Adolescent stressors, coping strategies, and psychological health studied in the family context. Journal of Youth and Adolescence, 29(1), 15-43.

Radeke, T., \& Smith, A. L. (2004). Copoing resources and athlete burnout: An examination of stress mediated and moderation hypotheses. Journal of Sport \& Exercise Psychology, 26(4), 525-541.

Rew, L., Johnson, K., \& Young, C. (2014). A systematic review of interventions to reduce stress in adolescence. Issues in Mental Health Nursing, 35(11), 851863. doi:10.3109/01612840.2014.924044

Rumbold, J. L., Fletcher, D., \& Daniels, K. (2012). A systematic review of stress management interventions with sport performers. Sport, Exercise, and Performance Psychology, 1(3), 173-193. doi:10.1037/a0026628

Sarkar, M., \& Fletcher, D. (2014). Psychological resilience in sport performers: a review of stressors and protective factors. Journal of Sports Sciences, 32(15), 1419-1434. http://doi.org/10.1080/02640414.2014.901551

Smith,J. A., Larkin, M. H., \& Flowers, P. (2009). Interpretative Phenomenological Analysis: Theory, Method and Research. Thousand Oaks, CA/London, SAGE.

Smith, A. L., Gustafsson, H., \& Hassmén, P. (2010). Peer motivational climate and burnout perceptions of adolescent athletes. Psychology of Sport and Exercise, 11(6), 453-460. doi:10.1016/j.psychsport.2010.05.007

Stambulova, N. B., \& Wylleman, P. (2015). Dual career development and transitions. Psychology of Sport and Exercise, 21, 1-3. doi:10.1016/j. psychsport.2015.05.003 
Stelter, R. (2010). Experience-based, body-anchored qualitative research interviewing. Qualitative Health Research, 20(6), 859-867. doi: $10.1177 / 1049732310364624$

Stelter, R., Nielsen, G., \& Wikman, J. M. (2011). Narrative-collaborative group coaching develops social capital - a randomised control trial and further implications of the social impact of the intervention. Coaching: An International Journal of Theory, Research and Practice, 4(2), 123-137. http:// doi.org/10.1080/17521882.2011.598654

Streiner, D. L. \& Norman, G. R. (2008). Health measurement scales: A practical guide to their development and use. (4th ed.). New York: Oxford University Press.

Tabei, Y., Fletcher, D., \& Goodger, K. (2012). The relationship between organizational stressors and athlete burnout in soccer players. Journal of Clinical Sport Psychology, 6(2),146-165.

Williams, J. M. \& Harris, D. V. (2006). Relaxation and energizing techniques for regulation of arousal. In J. M. Williams (ed), Applied sport psychology. Personal growth to peak performance (pp. 285-305). New York, NY: McGraw-Hill.

Johan Michael WIKMAN, PhD, is an academic officer at the Centre for Team Sport and Health, Department of Nutrition, Exercise and Sport at University of Copenhagen, Denmark. His research interests are within the fields of talent development, sport psychological training, motivation for sport and exercise, and psychological consequences of sport and exercise.

\section{Corresponding author:}

Johan Michael Wikman

Department for Nutrition, Exercise and Sports

University of Copenhagen

Nørre Allé 51, 2200 Kbh N

Phone: +4535320801

Email: jmwikman@nexs.ku.dk

Knud RYOM is an associated professor at the Department of Public Health, Humanistic Sport Research at Aarhus University in Denmark. His research interests lie in the broader area of sport and exercise psychology, mainly sport and integration, coaching and talent development. He is currently president of DIFO (Danish Sports Psychological Forum). 
Effects of a School-Based Relaxation Intervention on Recovery in Young Elite Athletes in High School

Reinhard STELTER, PhD, is a Professor at Department of Nutrition, Exercise and Sport at University of Copenhagen, Denmark. His research interests lie in Coaching Psychology, Sport and Exercise Psychology, Learning, Identity and self-concept, Mindfulness and Qualitative and narrative research.

Anne-Marie ELBE, PhD, is an Associate Professor for Sport and Exercise Psychology at the University of Copenhagen, Denmark. Her publications and research interests focus on motivational and self-regulatory aspects of athletic performance, talent development, doping and the integrative role of sport. She is President of FEPSAC, the European Federation of Sport Psychology. 